LA-UR-01-6735

Approved for public release; distribution is unlimited.

\section{Phase Diagram Studies in the SrO-CuO-TiO2 System; Applications to YBCO Coated Conductors}

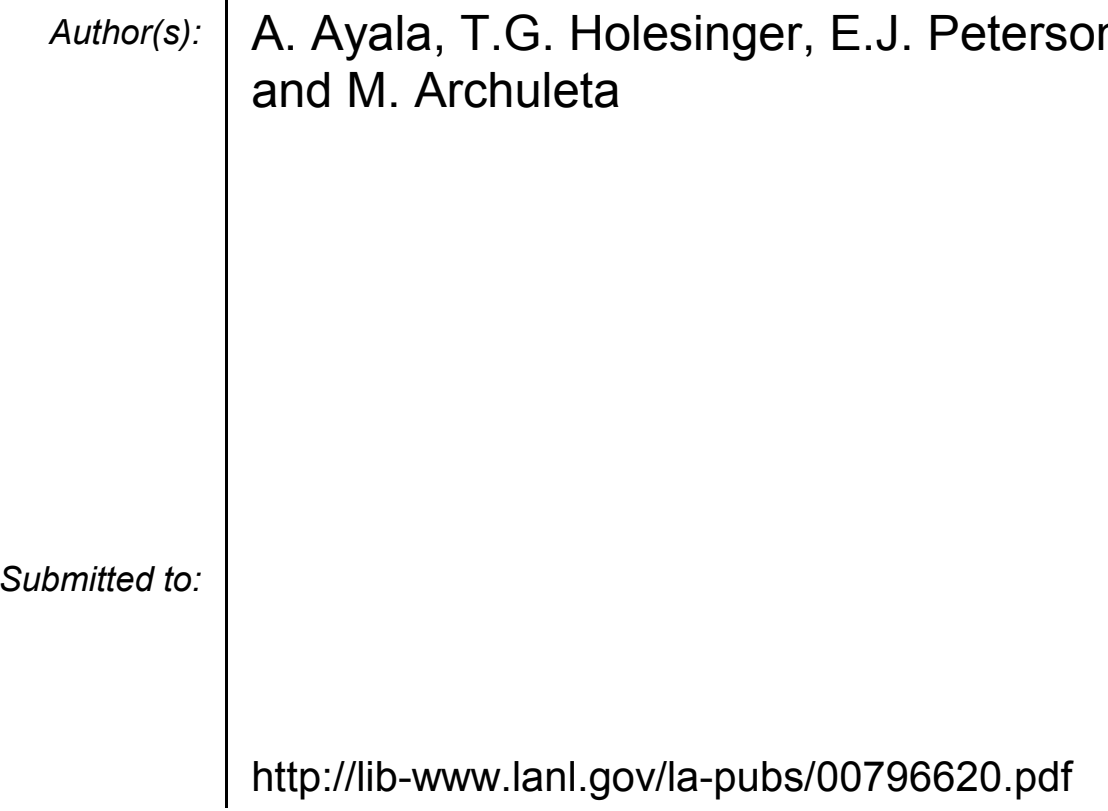




\title{
Phase Diagram Studies in the SrO-CuO-TiO 2 System; Applications to YBCO Coated Conductors
}

A. Ayala, T.G. Holesinger, E.J. Peterson, and M. Archuleta

Materials Science and Technology Division, Los Alamos National Laboratory, Los Alamos, NM 87545 U.S.A.

\begin{abstract}
$\mathrm{SrTiO}_{3}(\mathrm{STO})$ is a potential buffer layer material for use in $\mathrm{YBa}_{2} \mathrm{Cu}_{3} \mathrm{O}_{\mathrm{y}}(\mathrm{YBCO})$ coated conductors based on the IBAD MgO process. However, the interactions with YBCO are not yet fully understood and little information exists in the way of phase diagrams. With this in mind, the tie-line between $\mathrm{STO}$ and $\mathrm{SrCuO}_{2}$ in the pseudo-ternary system $\mathrm{SrO}-\mathrm{CuO}-\mathrm{TiO}_{2}$ was investigated. Phase assemblages and compositions were determined by $\mathrm{x}$-ray diffraction and electron microscopy in the temperature range of $1000^{\circ} \mathrm{C}$ to $1100^{\circ} \mathrm{C}$ in oxygen partial pressures of $1 \%, 10 \%$, and $100 \%$. Preliminary results showed that an appreciable amount of copper substitutes into the STO crystal structure. Conversely, Ti substitution into the $\mathrm{SrCuO}_{2}$ phase was not detected.
\end{abstract}

\section{INTRODUCTION}

$\mathrm{YBa}_{2} \mathrm{Cu}_{3} \mathrm{O}_{\mathrm{y}}(\mathrm{YBCO})$ coated conductors typically consist of three parts: a textured template, an intervening buffer layer(s), and the superconducting film[1-3]. One method of developing a textured template is to deposit a textured film on a polycrystalline substrate using ion-beam-assist-deposition (IBAD) [4]. Yttria-stablized zirconia (YSZ) is the most common film deposited by IBAD for the textured template. However, IBAD MgO has recently received a significant amount of attention in that the latter process is 100 times faster than IBAD YSZ in forming the textured film $[5,6]$.

A reason that IBAD MgO is not more widespread is that some difficulty has been encountered in developing a suitable and reliable intervening buffer layer on to which YBCO can be deposited. $\mathrm{SrTiO}_{3}$ (STO) is a candidate material for the intervening buffer layer. Highquality YBCO films are routinely grown on single-crystal STO substrates. However, little is known about the reactivity between YBCO and STO. While the latter problem rarely appears during deposition onto single crystal substrates, the deposition of YBCO onto a textured, polycrystalline film of STO may change this behavior. With this in mind, the investigation of the $\mathrm{SrO}-\mathrm{CuO}-\mathrm{TiO}_{2}$ psuedo-ternary phase diagram was started. There is no information in the literature regarding this particular phase diagram. In the present work, an emphasis was placed on the tie-line between $\mathrm{STO}$ and $\mathrm{SrCuO}_{2}$.

\section{EXPERIMENTAL PROCEDURE}

The starting materials used for powder preparations were $99.999 \%$ pure $\mathrm{SrCO}_{3}, \mathrm{CuO}$, and $\mathrm{TiO}_{2}$. Three precursor powders of $\mathrm{SrCu}_{\mathrm{x}} \mathrm{Ti}_{\mathrm{y}} \mathrm{O}_{\mathrm{z}}$ and two samples for use as standards $\left(\mathrm{SrCuO}_{2}\right.$, STO) were prepared. The precursor powder compositions are $\mathrm{SrCu}_{0.1} \mathrm{Ti}_{0.9} \mathrm{O}_{\mathrm{x}}($ sample 1), $\mathrm{SrCu}_{0.5} \mathrm{Ti}_{0.5} \mathrm{O}_{\mathrm{x}}$ (sample 2), and $\mathrm{SrCu}_{0.2} \mathrm{Ti}_{0.9} \mathrm{O}_{\mathrm{x}}$ (sample 3). The two standards and sample 1 were prepared by mixing calculated proportions of the starting materials in isopropanol in a motorized 

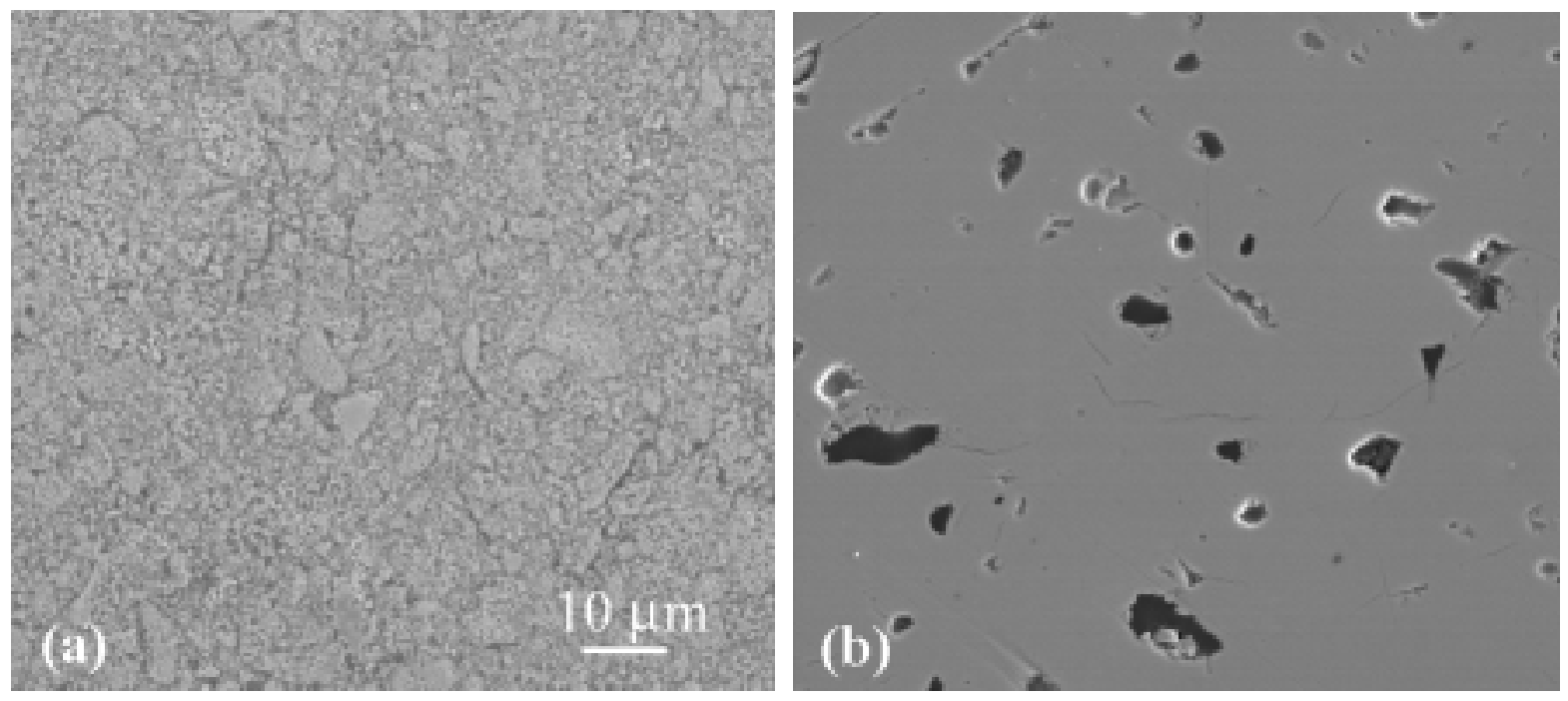

Figure 1. SEM backscattered electron micrographs of the (a) $\mathrm{STO}$ and (b) $\mathrm{SrCuO}_{2}$ standards used in the compositional quanitification process in the TEM. The uniform contrast indicates that both samples were single phase in agreement with the XRD results.

mortar and pestle for 4 hours. The solution was dried on a vacuum line using liquid nitrogen traps to collect the liquid. Samples 2 and 3 were dissolved in dilute nitric acid solution and mixed for 12 hours. The drying process was carried out as mentioned before. The dried powders were then pressed into 1-inch pellets and thermally processed several times with intermittent grindings and pressings. The STO standard was initially treated at $900^{\circ} \mathrm{C}$ for 10 hours, followed by 2 additional treatments at higher temperatures (10 hours each). The $\mathrm{SrCuO}_{2}$ standard was initially treated at $800^{\circ} \mathrm{C}$ for 10 hours followed by 2 additional treatments at $1000^{\circ} \mathrm{C}$ (each for 10 hours).

For sample 1, two heat treatments were carried out at $1050^{\circ} \mathrm{C}$ in oxygen for a total of 20 hours. Some of this powder was then used to press two 0.5 -inch pellets. The pellets were treated at $1050^{\circ} \mathrm{C}$ for 50 hours, one at $10 \% \mathrm{P}\left(\mathrm{O}_{2}\right), 90 \% \mathrm{Ar}$ and the other at $100 \% \mathrm{P}\left(\mathrm{O}_{2}\right)$. In the case of samples 2 and 3, the first heat treatment was performed on the as-dried powders at $600^{\circ} \mathrm{C}$ in air for 5 hours with the purpose of decomposing any remaining nitrates. Sample 2 was then treated at $1050^{\circ} \mathrm{C}$ for 10 hours. Two samples of this batch were then treated at the $\mathrm{O}_{2}$ partial pressures previously specified for 50 hours. Sample 3 was treated in a similar manner. X-ray diffraction was used to determine the phases present in the resulting powders. Scanning and transmission electron microscopy (SEM and TEM) were used to characterize the powders. The Cliff-Lorimer ratio method was used to quantify atomic percentages of the individual elements in samples 1,2 , and 3 using the pure STO and $\mathrm{SrCuO}_{2}$ powders as standards [7].

\section{DISCUSSION}

The overall microstructures of the standards and pressed pellets of samples 1, 2, and 3 processed in $100 \% \mathrm{P}\left(\mathrm{O}_{2}\right)$ are shown in Figures 1(a)-1(b) and Figures 2(a)-2(f), respectively. XRD and SEM both confirmed the phase purity of the standard materials that where subsequently used in the EDS quantification process in the TEM. In Figure 2, the column on the 

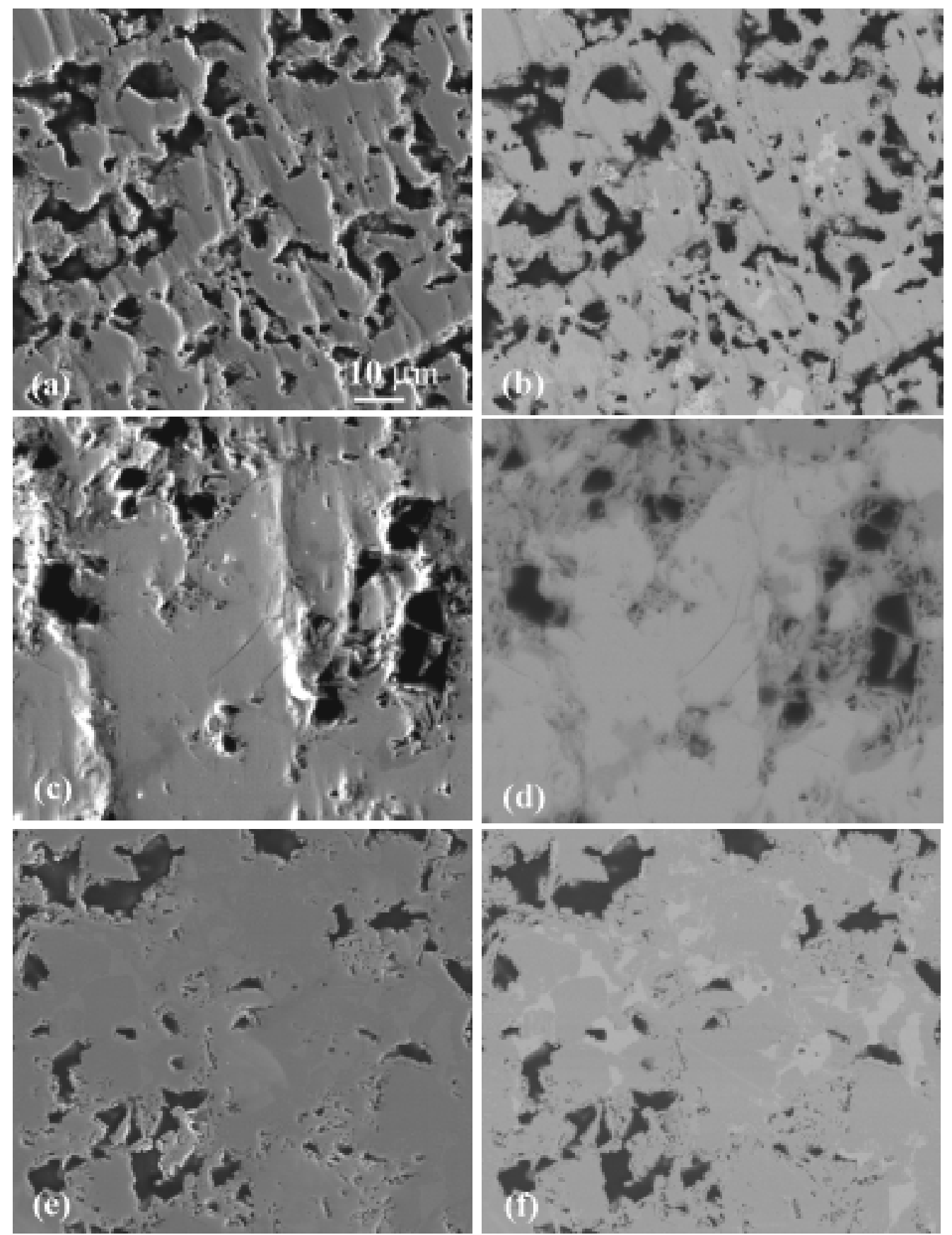

Figure 2. SEM secondary and backscattered micrographs of overall microstructure of the three samples after processing at $1050^{\circ} \mathrm{C}$ in $\mathrm{O}_{2}$. Samples 1,2 , and 3 are $\mathrm{SrCu}_{0.1} \mathrm{Ti}_{0.9} \mathrm{O}_{\mathrm{x}}$, (a) and (b), $\mathrm{SrCu}_{0.5} \mathrm{Ti}_{0.5} \mathrm{O}_{\mathrm{x}},(\mathrm{c})$ and (d), and $\mathrm{SrCu}_{0.2} \mathrm{Ti}_{0.9} \mathrm{O}_{\mathrm{x}}$, (e) and (f).

left shows the secondary electron image and the right column depicts the corresponding backscattered image. In general the pellets exhibited a rather porous structure.

For sample 1, Figure 2(b) reveals the presence of a secondary phase. Corresponding x-ray map analysis confirmed that this was a $\mathrm{Cu}$-rich phase (lighter area), which was presumed to be $\mathrm{SrCuO}_{2}$. The latter secondary phase was not detectable by XRD under any of the processing 

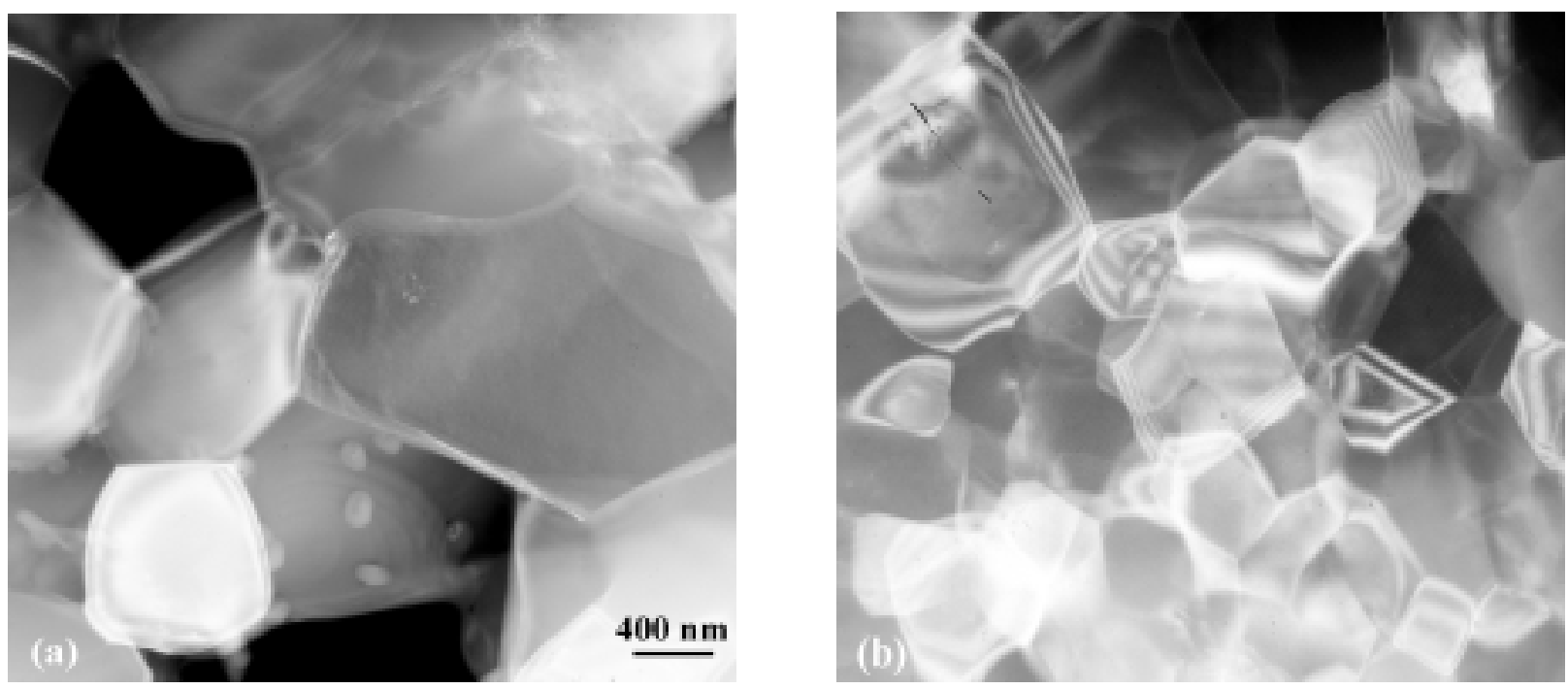

Figure 3. TEM micrographs of (a) sample 1 and (b) sample 3 illustrating the difference in grain size.

conditions used indicating that samples of the composition $\mathrm{SrCu}_{0.1} \mathrm{Ti}_{0.9} \mathrm{O}_{\mathrm{x}}$ were nearly single phase.

Figure 2(d) shows that in the case of sample 2, $\mathrm{SrCu}_{0.5} \mathrm{Ti}_{0.5} \mathrm{O}_{\mathrm{x}}$, the quantity of secondary phase is much greater than that seen in sample 1 when processed under the same conditions. Xray mapping also revealed that this secondary phase is $\mathrm{Cu}$-rich. Results of XRD analysis showed that sample 2 is composed of 2 phases, STO and $\mathrm{SrCuO}_{2}$. This same set of phases was present in all of the samples of this composition processed under the various oxygen partial pressures at $1050^{\circ} \mathrm{C}$.

For sample 3, $\mathrm{SrCu}_{0.2} \mathrm{Ti}_{0.9} \mathrm{O}_{\mathrm{x}}$, Figure 2(f) shows that small amounts of a Cu-rich phase, presumably $\mathrm{SrCuO}_{2}$, could be found in the matrix. The amount of this phase did not appear to change as a function of the oxygen partial pressure during processing. XRD analysis of sample3 did not detect the $\mathrm{SrCuO}_{2}$ or any other secondary phases.

Figure 3 provides a brief view of some of the microstructures as seen by TEM. Figure 3(a) shows that of Sample 1 and (b) corresponds to Sample 3. Although processed under identical conditions, the composition of sample 1 resulted in a larger grain size in the sintered samples. By EDS analysis, it was shown that copper was substituting into the STO crystal structure, apparently for the titanium. The measured composition of the STO phase in samples 1, 2, and 3 were $\mathrm{Sr}_{1.01} \mathrm{Ti}_{0.96} \mathrm{Cu}_{0.03} \mathrm{O}_{\mathrm{y}}, \mathrm{Sr}_{1.04} \mathrm{Ti}_{0.92} \mathrm{Cu}_{0.04} \mathrm{O}_{\mathrm{y}}$, and $\mathrm{Sr}_{1.01} \mathrm{Ti}_{0.95} \mathrm{Cu}_{0.03} \mathrm{O}_{\mathrm{y}}$, respectively. TEM/EDS analysis of sample 2 confirmed the presence of two distinct phases within the microstructure. Figure 4(a) shows that some $\mathrm{Cu}$ is present in the STO matrix. In contrast, Figure 4(b) shows that the $\mathrm{SrCuO}_{2}$ phase is Ti free within the limits of the EDS system. This is an indication that $\mathrm{Cu}$ can diffuse into STO, but Ti apparently doesn't substitute into $\mathrm{SrCuO}_{2}$.

Further work is planned to fully investigate the psuedo-ternary phase diagram $\mathrm{SrO}-\mathrm{CuO}-\mathrm{TiO}_{2}$ and clearly define the limits of the solid solubility of the various elements in the phases present. However, it is clear that $\mathrm{Cu}$ can substitute into the STO crystal structure to an appreciable degree. This is an important point to consider in the processing of YBCO coated conductors with STO buffer layers as interfacial reactions are a prime cause for degradation of the superconducting transport properties in these composites [8]. 


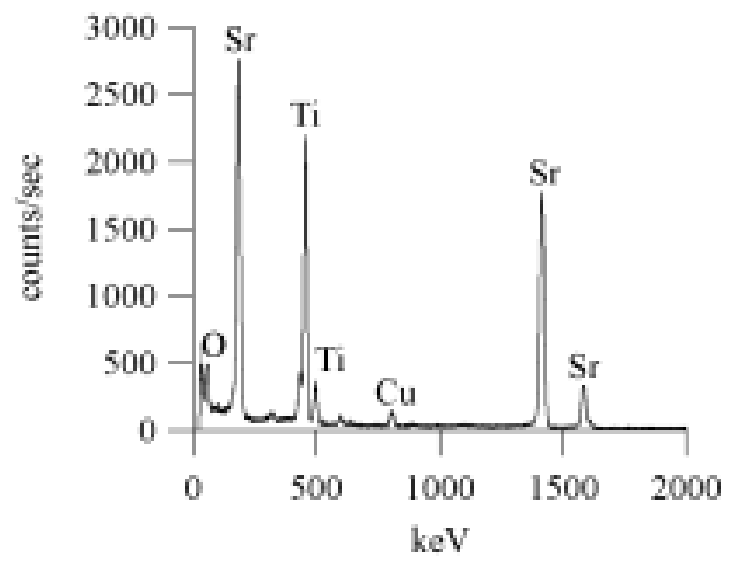

(a)

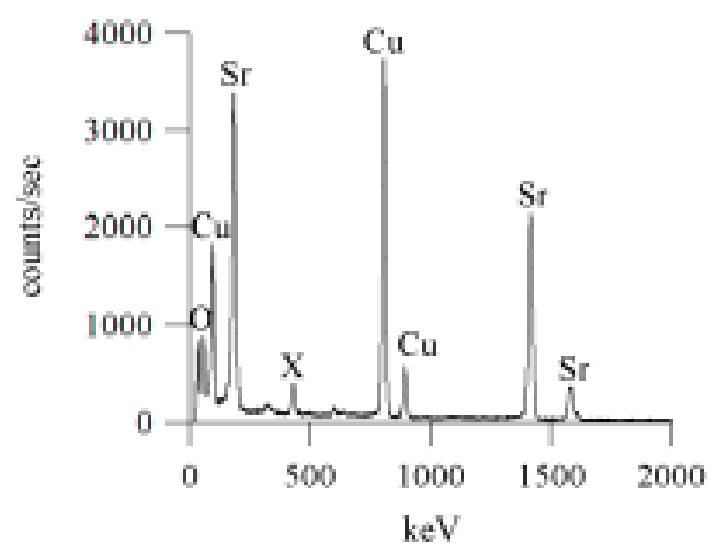

(b)

Figure 4. EDS analysis of sample 2 confirmed the presence of distinct phases within the structure (X denotes artifact peak). (a) EDS data shows that some $\mathrm{Cu}$ diffused into the $\mathrm{STO}$ phase. (b) $\mathrm{The} \mathrm{SrCuO}_{2}$ phase is apparently Ti-free, within the limits of the EDS system.

\section{SUMMARY}

The tie line between $\mathrm{STO}$ and $\mathrm{SrCuO}_{2}$ was investigated in the psuedo-ternary $\mathrm{SrO}-\mathrm{CuO}-\mathrm{TiO}_{2}$ phase diagram. The only two phases identified were $\mathrm{STO}$ and $\mathrm{SrCuO}_{2}$ in the samples prepared along the tie-line. Copper was found to substitute into STO crystal structure to the level of at least 2.5 molar percent and possibly up to 5 molar percent. Based on the measured compositions, it appeared to substitute for the titanium in the structure. Conversely, titanium did not appear to substitute into the $\mathrm{SrCuO}_{2}$ structure.

\section{ACKNOWLEDGMENT}

This work was performed under the auspices of the United States Department of Energy (DOE), Office of Energy Efficiency and Renewable Energy, as part of a DOE program to develop electric power technology, under Contract No. W-7405-ENG-36.

\section{REFERENCES}

1. Y. Iijima, N Tanabe, O. Kohno, and Y. Ikeno, Applied Physics Letters 60 (6), 769-771 (1992).

2. X.D. Wu, S.R. Foltyn, P. Arendt, J. Townsend, C. Adams, I.H. Campbell, P. Tiwari, Y. Coulter, and D.E. Peterson, Applied Physics Letters 65 (15), 1961-1963 (1994).

3. A. Goyal, D.P. Norton, J.D. Budai, M. Paranthaman, E.D. Specht, D.M. Kroeger, D.K. Christen, Q. He, B. Saffian, F.A. List, D.F. Lee, P.M. Martin, C.E. Klabunde, E. Hartfield, and V.K. Sikka, Applied Physics Letters 69 (12), 1795-1797 (1996).

4. P.N. Arendt, S.R. Foltyn, J.R. Groves, R.F. Depaula, P.C. Dowden, J.M. Roper, and J.Y. Coulter, Applied Superconductivity 4 (10-11), 429-434 (1996). 
5. C.P. Wang, K.B. Do, M.R. Beasley, T.H. Geballe, and R.H. Hammond, Applied Physics Letters 71, 2955-2957 (1997).

6. J.R. Groves, P.N. Arendt, S.R. Foltyn, R.F. DePaula, E.J. Peterson, T.G. Holesinger, J.Y. Coulter, R.W. Springer, C.P. Wang, and R.H. Hammond, IEEE Transactions on Applied Superconductivity 9 (2), 1964-1966 (1999).

7. G. Cliff and G.W. Lorimer, Journal of Microscopy 103, 203 (1975).

8. T.G. Holesinger, S.R. Foltyn, P.N. Arendt, Q. Jia, P.C. Dowden, R.F. DePaula, and J.R. Groves, IEEE Transactions on Applied Superconductivity 11 (1), 3359-3364 (2001). 